\title{
Knowledge, Attitude and Practices of Adults on Cholesterol Management in CALABARZON Region
}

\author{
Diorella Marie M. Tria, MSc, ${ }^{1,2}$ Leila S. Africa, RND, PhD, ${ }^{1}$ \\ Aimee Sheree A. Barrion, RND, $\mathrm{PhD}^{1}$ and April Shayne L. Sulabo, $\mathrm{PhD}^{3}$ \\ ${ }^{1}$ Institute of Human Nutrition and Food, College of Human Ecology, University of the Philippines, Los Baños, Laguna, Philippines \\ ${ }^{2}$ Graduate School, University of the Philippines, Los Baños, Laguna, Philippines \\ ${ }^{3}$ Institute of Food Science and Technology, College of Agriculture and Food Science, University of the Philippines, Los Baños, Laguna, Philippines
}

\begin{abstract}
Background and Objectives. High levels of total cholesterol, according to the Food and Nutrition Research Institute, are among the top significant contributing factor for cardiovascular diseases (CVDs). The awareness of cholesterol at the community level is critical in potential prevention and preparedness. This paper aimed to assess the level of knowledge, attitude, and practices (KAP) of adults on cholesterol management to determine their risk to CVD.
\end{abstract}

Methods. The study targeted employed populations (20 to 55 years old) who were undiagnosed with hypercholesterolemia and other severe chronic diseases. The participants were categorized based on their work mobility: (a) sedentary; and (b) active. KAP scores were predefined as high, moderate, low, and very low risk.

Results. Results showed that $52 \%$ of the participants had excellent overall knowledge, attitude, and practice (KAP) scores, thus had the lowest risk of developing hypercholesterolemia. However, $28 \%$ resulted in having the highest risk among the population.

Conclusion. The results of this study showed the level of good KAP among employed adults to be relatively high. Despite the gaps in KAP measurement, respondents showed interest in cholesterol-lowering interventions. Further studies are therefore necessary to fill the findings with a more concrete resolution.

Key Words: knowledge, attitudes, and practices questionnaire, cholesterol, cardiovascular diseases, public health, crosssectional study

\section{INTRODUCTION}

There is substantial evidence that an elevated prevalence of hypercholesterolemia is found to those groups of individuals at high cardiovascular risk. ${ }^{1}$ Cholesterol-lowering guidelines and other effective treatments had resulted in a reduction of cardiovascular incidents in various preventions. However, significant gaps in the awareness in cholesterol management restrain the implementation of such guidelines and treatments to prevent hypercholesterolemia. It has also been noted that for every percentage of the population who are at risk of cardiovascular diseases (CVDs) due to elevated cholesterol levels in the body, almost $50 \%$ were unaware of their condition. The World Health Organization had also stated that only $36 \%$ is the average rate of cholesterol awareness in both genders. ${ }^{2}$ It is an

Corresponding author: Diorella Marie M. Tria, MSc Institute of Human Nutrition and Food

College of Human Ecology

University of the Philippines

Los Baños, Laguna, Philippines 4031

Email:dmtria@up.edu.ph alarming situation that even those patients who are at high risk had poor compliance with cholesterol-lowering therapy. ${ }^{3}$ The relationship between CVD and blood cholesterol has been established for many decades now, and the prevalence of CVD among the population is progressively increasing, 
making it the leading cause of mortality worldwide. The management of cardiovascular health from every country has been a burden that is why governments and international organizations have started to implement preventive actions on the population level. ${ }^{4}$ The public's awareness and knowledge of beneficial treatments for the risk factor management of cholesterol at the community level are critical in potential prevention and preparedness as a result of monitored everyday practice and routines. It is beneficial for the study to obtain general information about public health awareness regarding prevention practices to developing CVD; thus, Knowledge, Attitude, and Practices (KAP) survey will be used. A KAP survey is a predefined set of questions that provide access to quantitative and qualitative information. This paper aimed to assess the level of knowledge, attitude, and practices of adults on cholesterol management to determine their risk of cardiovascular diseases.

\section{MATERIALS AND METHODS}

\section{Study Design}

The assessment was a cross-sectional study that involved adults currently employed in a company with different work assignments. The study was conducted in the provinces of Cavite, Laguna, and Batangas, representing the region of CALABARZON. The area is the most populous in the country, and due to its proximity to Metro Manila, urbanization has taken place over the years. Also, CALABARZON is known to be the site of most food manufacturing and high-tech industries. The study focused on the top 3 provinces with the highest number of populations to represent the region - Cavite (25.5\%), Laguna (21.1\%), and Batangas (18.7\%). ${ }^{5}$ The study was designed to determine the level of an individual's knowledge, attitude, and practices on cholesterol management and to assess one's risk of having an abnormal level of cholesterol affecting his cardiovascular health. A pre-developed 40-item questionnaire was given to every participant. The study targeted populations based on the following criteria: (1) within the age range set for the study (20 to 55 years old); (2) no communicable disease; (3) undiagnosed of hypercholesterolemia; (4) had satisfied the requirements set on the general consent form. The basis of the diagnosis of hypercholesterolemia of the participants was from the self-reported information from the initial screening. The participants were categorized based on their normal mobility during work hours: (a) sedentary; and (b) active, based on the American College of Sports Medicine's (ACSM) public health guidelines for physical activity. "Sedentary" is defined as a lifestyle with moderate to intense activities for at least 30 minutes for $<5$ days/week and $\geq 5$ days/week for "active". ${ }^{6}$

\section{Sampling Procedure}

Stratified random sampling (SRS) was used to select the participants with the type of company and nature of their work as strata by randomization $(\mathrm{N}=263)$. Subjects representing each company were pre-assessed to ensure that they will satisfy the requirements set on the general consent form. Companies X, Y, and Z, were surveyed before the study. Consent forms and the schedule for the data collection were distributed. Pre-orientation was conducted to explain the content of the consent form, the objectives of the study and what it intends to measure. Cochran's formula,

$$
n_{0}=\frac{z^{2} p q}{e^{2}}
$$

was used to determine the sample size where, $n_{0}$ is the sample size, $z$ was the selected critical value of desired confidence level, $p$ was the estimated proportion of an attribute present in the population, $q$ is $1-p$ and $e$ was the desired level of precision. The sample size was calculated with a $95 \%$ confidence level and a 5\% marginal error. ${ }^{7}$

\section{Instrument development}

Published manuscripts, documentations, and journals since 2010 that contained information on cholesterols, $\mathrm{CVD}$, and its risk factors were considered. Modifiable risks and health threats led by cholesterols and its relation to an individual's vascular health were identified. The age group determined the target age group with the most number of incident cases and the highest risk to hypercholesterolemia. An expert panel was part of the systematic review in every stage of the revision.

The number of questions was reduced based on the necessary revisions. The resulting 40-item questionnaire was categorized under five (5) sections: (a) Basic profile; (b) Cholesterol knowledge; (c) Foods and cholesterol; (d) Cholesterol risk factors and practices; and (e) Attitude for a healthy lifestyle. These sections were intended to measure the level of KAP of the participants on cholesterol management, with the scope of outcomes as follows: knowledge about basic cholesterol facts, knowledge about foods that must and must not be avoided to improve or maintain cholesterol levels in the body, medical history, medical practices, lifestyle practices, and interest or plans to improve lifestyle. The validity of the questionnaire was measured by the content validity index (CVI) to determine the relevancy and clarity of each item. ${ }^{8}$ Cohen's kappa coefficient $(\kappa)$ was used to determine the inter-rater reliability among the experts. ${ }^{9}$ The resulting questionnaire with satisfactory content validity was subjected to pilot testing to assess its reliability for data collection. Random subjects (N=50) in Laguna were selected based on the same inclusion criteria used in the screening for the sampling procedure of this study. The reliability and consistency of the items were assessed using Cronbach's alpha to determine the relation of all items in every category of the questionnaire. ${ }^{10}$ The alpha for all the sections resulted in having a value within the desirable range. The detailed procedure for the development of the questionnaire used in this study will be available in another journal. 
Table 1. Operational definition of terms

\begin{tabular}{|c|c|}
\hline Term & Definition \\
\hline Risk factors & Variables that are associated with an increased risk of disease or condition \\
\hline $\begin{array}{l}\text { Knowledge } \\
\text { (on cholesterol management) } \\
\text { [sections B/C of questionnaire] }\end{array}$ & $\begin{array}{l}\text { Definition: } \\
\text { Awareness or well-informed interest about maintaining normal levels of cholesterol in the body } \\
\text { Good Knowledge Score: } \\
\text { A score point with }>50 \% \text { as the average (combined scores from sections B \& C) passing score which } \\
\text { determines if a respondent has background knowledge about cholesterol facts } \\
\text { Poor Knowledge Score: } \\
\text { A score point with }<50 \% \text { as the average }\end{array}$ \\
\hline $\begin{array}{l}\text { Attitude } \\
\text { (on cholesterol management) } \\
\text { [section E of questionnaire] }\end{array}$ & $\begin{array}{l}\text { Definition: } \\
\text { A settled way of thinking about the perception and what actions one's own should follow which would reflect } \\
\text { his behavior towards management } \\
\text { Good Attitude Score: } \\
\text { A score point with }>50 \% \text { as the average passing score which determines if a respondent exhibits a lifestyle of } \\
\text { being healthy } \\
\text { Poor Attitude Score: } \\
\text { A score point with }<50 \% \text { as the average which determines if a respondent exhibits a lifestyle of being } \\
\text { unhealthy as one of the factors of CVDs }\end{array}$ \\
\hline $\begin{array}{l}\text { Practices } \\
\text { (on cholesterol management) } \\
\text { [section D of questionnaire] }\end{array}$ & $\begin{array}{l}\text { Definition: } \\
\text { Actual application of one's repeated activity which in turn becomes habit or routine } \\
\text { Good Practice Score: } \\
\text { A score point with }>50 \% \text { as the average passing score which determines if a respondent is at low risk to } \\
\text { hypercholesterolemia } \\
\text { Poor Practice Score: } \\
\text { A score point with }<50 \% \text { as the average which determines if a respondent is at high risk to hypercholesterolemia }\end{array}$ \\
\hline Overall KAP scores & $\begin{array}{l}\text { Very low risk KAP score: } \\
\text { Passed in all knowledge }(>50 \%) \text {, attitude }(>50 \%) \text { and practice }(>50 \%) \text { scores } \\
\text { Low risk KAP score: } \\
\text { Failed in either knowledge or attitude score } \\
(\mathrm{K}=<50 \%, \mathrm{~A}=>50 \%) \text { or }(\mathrm{K}=>50 \%, \mathrm{~A}=<50 \%) \\
\text { Moderate risk KAP score: } \\
\text { Failed in both knowledge }(<50 \%) \text { and attitude }(<50 \%) \text { scores } \\
\text { High risk KAP score: } \\
\text { Failed in all knowledge }(<50 \%) \text {, attitude }(<50 \%) \text { and practice }(<50 \%) \text { scores or Failed in practice }(<50 \%) \text { score only }\end{array}$ \\
\hline
\end{tabular}

\section{Assessment and Interpretation}

Knowledge, attitude, and practice levels were analyzed through the combined scores of the questionnaire. Further interpretations were made based on the assessment of overall KAP scores (Table 1).

\section{Statistical Analysis}

IBM SPSS v25.0 was used to analyze the data. Summary statistics were done for all data. The scoring system of the questionnaire guided results for the response analysis. T-test was performed for independent variables to determine the difference in risk level among adult employees with varying work mobility in terms of their mean knowledge. The Wilcoxon rank-sum test determined the difference between the attitudes of sedentary and active workers. And for the difference among their practices in life, the Chisquare test was used. ${ }^{7}$ Different statistical analyses were used to examine the relationship of risk to hypercholesterolemia with the socioeconomic factors, working mobility, knowledge, attitude, and practices. Pearson's correlation was used for interval or ratio data, Spearman's correlation for questions with ordinal items, Eta coefficient for nominal data, and Chi-square for the test of independence among variables. Associations were considered significant at a value of $\mathrm{p}<0.05 .^{7}$

\section{Ethical considerations}

Before initiation of the study, the University of the East Ramon Magsaysay Memorial Medical Center, Inc. ethical committee approved this study with RIHS code: 0634/E/O/18/145.

\section{RESULTS}

\section{Profile Characteristics of Participants}

Based on the analysis, $48.3 \%$ were male, while $51.7 \%$ were female $(\mathrm{N}=263)$ and that the majority of the participants were within the age range of "20-40s. Moreover, majorities were college graduates, including post-college (46.3\%). The least percentage of the population (20.1\%), however, has reported monthly household income below the average salary rate in the country. The majority was observed to single participants without a child (62\%).

Meanwhile, only $2.7 \%$ were currently taking medications as maintenance. The result showed that a higher percentage of the population was considered to be active workers (61.6\%) (Table 2). 
Table 2. Profile characteristics of the respondents

\begin{tabular}{llr}
\hline \multicolumn{1}{c}{ Characteristics } & \multicolumn{1}{c}{ Indicators } & \multicolumn{1}{c}{ Total } \\
& Male & $127(48.3 \%)$ \\
& Female & $136(51.7 \%)$ \\
\hline Age group & $20-30$ years & $151(57.4 \%)$ \\
& $31-40$ years & $84(31.9 \%)$ \\
& $41-50$ years & $13(4.9 \%)$ \\
& $>50$ years & $15(5.7 \%)$ \\
\hline Educational Attainment & Elementary graduate & $2(0.8 \%)$ \\
& High school graduate & $92(35.0 \%)$ \\
& College level & $47(17.9 \%)$ \\
& College graduate & $109(41.4 \%)$ \\
& Post graduate & $13(4.9 \%)$ \\
\hline Monthly household & $<10,000$ & $53(20.1 \%)$ \\
income (Php) & $10,000-20,000$ & $96(36.5 \%)$ \\
& $20,001-40,000$ & $56(21.3 \%)$ \\
& $>40,000$ & $58(22.1 \%)$ \\
\hline Civil status & Single (with child) & $9(3.4 \%)$ \\
& Single (w/o child) & $163(62.0 \%)$ \\
& Married (with child) & $56(21.3 \%)$ \\
& Married (w/o child) & $31(11.8 \%)$ \\
& Widowed (with child) & $3(1.1 \%)$ \\
& Widowed (w/o child) & $1(0.4 \%)$ \\
\hline Current maintenance & Yes & $7(2.7 \%)$ \\
in medications & No & $256(97.3 \%)$ \\
\hline Working Mobility & Active & $162(61.6 \%)$ \\
& Sedentary & $101(38.4 \%)$ \\
\hline & & \\
& & \\
& & \\
& &
\end{tabular}

\section{Knowledge, Attitude, and Practice}

The majority (85.2\%) of participants had a good knowledge score. The majority (76.0\%) also had a good attitude score that exhibits a lifestyle of being healthy in general. The section of the questionnaire that measured the attitude level was constructed to assess the intention of negative habit subjects to change every harmful habit they have to improve their lifestyle. A high percentage (71.9\%) was also observed to good practice score points (Table 3). However, scores from some specific practice questions were relatively low in contrast to knowledge and attitude assessment. The practices that had the lowest rate of implementation are regular cholesterol checking, monitoring one's cholesterol numbers, and consistent blood pressure measurement.

\section{Overall KAP}

Results indicated that $51.7 \%$ of the participants had an excellent overall KAP score and can be considered to have a very low risk of developing hypercholesterolemia. However,
$28.1 \%$ of the population was found at the highest risk of developing an increased level of cholesterol in the body. It was also observed that $17.5 \%$ got low-risk scores, while $2.7 \%$ of the population got an average risk score (Table 4).

\section{Summary Statistics of KAP according to working mobility}

Following ACSM's guidelines for physical activity, results show that the majority were active workers. Statistical data of active and sedentary workers for knowledge showed significant results, while the outcome for both attitude and practice scores showed insignificance (Table 3 ).

\section{Correlation of overall KAP scores according to respondent characteristics}

The overall KAP correlation to characteristics of the respondents indicated that the scores were dependent only on the variables sex (p-value: 0.029 ) and income ( $p$-value: 0.030). Comparisons with the FNRI survey in $2015^{11}$ showed that the female population was more at risk of high cholesterol levels due to the prevalence of obesity. Also, the population from the poorest wealth showed a higher occurrence of CVDs. Findings from this study regarding behavioral risks showed that the majority were at high risk to most practices. Among these said behavioral practices were cholesterol checking (42\%), exercising (47\%), smoking (76\%), and alcohol drinking (59\%) (Table 4).

\section{DISCUSSION}

This study assessed the KAP levels among working adults. Studies have shown that there is a direct implication to various lifestyles of different genders in terms of the quality of their lives. ${ }^{12}$ The local survey from FNRI revealed that females within the borderline cholesterol level are higher (35.2\%) than on males (26.8\%). ${ }^{11}$ The result of the correlation of KAP according to working mobility implied that the intensity of the physical activity was associated only with a more favorable level of knowledge on cholesterol management since insignificance was only observed to attitude and practice scores (Table 3). Over time, physical activity has been inversely related to fatal and non-fatal CVDs. ${ }^{13}$ There was very limited data on whether the Philippine population is well adept on the knowledge about properly managing cholesterol levels in the body. Data about the correlation of awareness and physical activity as a preventive measure to

Table 3. Summary statistics of KAP according to working mobility

\begin{tabular}{lcccc} 
& $\begin{array}{c}\text { Respondents with } \\
\text { good KAP scores }\end{array}$ & $\begin{array}{c}\text { Active Respondents } \\
\text { with good KAP scores }\end{array}$ & $\begin{array}{c}\text { Sedentary Respondents } \\
\text { with good KAP scores }\end{array}$ & Statistical Analysis \\
\hline Knowledge & $224(85.2 \%)$ & $129(79.6 \%)$ & $95(94.1 \%)$ & $p$-value: 0.0382 (Significant) \\
Attitude & $200(76.0 \%)$ & $128(79.0 \%)$ & $72(71.3 \%)$ & $p$-value: 0.1072 (Not Significant) \\
Practice & $189(71.9 \%)$ & $109(67.3 \%)$ & $80(79.2 \%)$ & $p$-value: 0.3285 (Not Significant) \\
\hline
\end{tabular}

*percentage is based from the total sub population of active and sedentary workers 
Table 4. The correlation of overall KAP risk scores to respondent characteristics

\begin{tabular}{|c|c|c|c|c|c|c|}
\hline \multirow{2}{*}{ Characteristics } & \multicolumn{4}{|c|}{ KAP risk scores } & \multirow{2}{*}{ p-value } & \multirow{2}{*}{ Interpretation } \\
\hline & Very low risk & Low risk & Moderate risk & High risk & & \\
\hline ALL & $136(51.7 \%)$ & $46(17.5 \%)$ & $7(2.7 \%)$ & $74(28.1 \%)$ & & \\
\hline Sex & & & & & 0.0290 & Significant \\
\hline Male & 45 (17.1\%) & 5 (1.9\%) & 21 (8.0\%) & 56 (21.3\%) & & \\
\hline Female & 29 (11.0\%) & $2(0.8 \%)$ & 25 (9.5\%) & $80(30.4 \%)$ & & \\
\hline Age (years) & & & & & 0.0630 & Not Significant \\
\hline $20-29$ & 37 (14.1\%) & 4 (1.5\%) & 29 (11.0\%) & $81(30.8 \%)$ & & \\
\hline $30-39$ & 30 (11.4\%) & $0(0 \%)$ & $13(4.9 \%)$ & $41(15.6 \%)$ & & \\
\hline $40-49$ & $3(1.1 \%)$ & $2(0.8 \%)$ & $3(1.1 \%)$ & $5(1.9 \%)$ & & \\
\hline$\geq 50$ & $4(1.5 \%)$ & $1(0.4 \%)$ & $1(0.4 \%)$ & $9(3.4 \%)$ & & \\
\hline Educational Attainment & & & & & 0.6530 & Not Significant \\
\hline Elementary Graduate & $0(0 \%)$ & $0(0 \%)$ & $0(0 \%)$ & $2(0.8 \%)$ & & \\
\hline High school Graduate & 30 (11.4\%) & $2(0.8 \%)$ & $18(6.8 \%)$ & $42(16.0 \%)$ & & \\
\hline College Level & $12(4.6 \%)$ & $0(0 \%)$ & $5(1.9 \%)$ & 30 (11.4\%) & & \\
\hline College Graduate & 29 (11.0\%) & $4(1.5 \%)$ & $21(8.0 \%)$ & 55 (20.9\%) & & \\
\hline Post Graduate & $3(1.1 \%)$ & $1(0.4 \%)$ & $2(0.8 \%)$ & $7(2.7 \%)$ & & \\
\hline Monthly Household Income (Php) & & & & & 0.0300 & Significant \\
\hline$<10,000$ & $11(4.2 \%)$ & $0(0 \%)$ & $8(3.0 \%)$ & $34(12.9 \%)$ & & \\
\hline $10,000-20,000$ & $25(9.5 \%)$ & $1(0.4 \%)$ & $19(7.2 \%)$ & $51(19.4 \%)$ & & \\
\hline $20,001-40,000$ & $13(4.9 \%)$ & $1(0.4 \%)$ & $8(3.0 \%)$ & $24(9.1 \%)$ & & \\
\hline$>40,000$ & $15(5.7 \%)$ & $5(1.9 \%)$ & $11(4.2 \%)$ & $27(10.3 \%)$ & & \\
\hline Civil Status & & & & & 0.1020 & Not Significant \\
\hline Single & 49 (18.6\%) & $3(1.1 \%)$ & 29 (11.0\%) & $91(34.6 \%)$ & & \\
\hline Married & $23(8.7 \%)$ & $3(1.1 \%)$ & $17(6.5 \%)$ & $44(16.7 \%)$ & & \\
\hline Widowed & $2(0.8 \%)$ & $1(0.4 \%)$ & $0(0 \%)$ & $1(0.4 \%)$ & & \\
\hline Working Mobility & & & & & 0.3290 & Not Significant \\
\hline Active & $40(15.2 \%)$ & $5(1.9 \%)$ & 27 (10.3\%) & 90 (34.2\%) & & \\
\hline Sedentary & 34 (12.9\%) & $2(0.8 \%)$ & $19(7.2 \%)$ & $46(17.5 \%)$ & & \\
\hline Behavioral Risk Factors & & & & & Not & ermined \\
\hline Cholesterol checking & $57(22 \%)$ & 44 (17\%) & $50(1 \%)$ & 112 (42\%) & & \\
\hline $\mathrm{BP}$ measurement & $4(2 \%)$ & $59(22 \%)$ & $177(67 \%)$ & $23(9 \%)$ & & \\
\hline Body weight monitor & $67(25 \%)$ & 91 (35\%) & $81(30 \%)$ & 24 (10\%) & & \\
\hline Exercise & 30 (11\%) & $36(14 \%)$ & $74(28 \%)$ & $123(47 \%)$ & & \\
\hline Smoking & $22(8 \%)$ & $23(9 \%)$ & $19(7 \%)$ & $199(76 \%)$ & & \\
\hline Alcohol drinking & $1(0 \%)$ & $36(14 \%)$ & $72(27 \%)$ & $154(59 \%)$ & & \\
\hline
\end{tabular}

${ }^{*} N \%$ - rate out of the total population of the study $(N=263)$

hypercholesterolemia towards CVD were limited as well. Several studies had shown the positive correlation of good knowledge and low risk to CVD development; however, some studies showed no significant difference to lack of awareness of blood cholesterol levels among those who were educated and non-educated. ${ }^{14}$ Concerning lifestyle modification, the results also implied that the attitude and practices of active workers were on an unexpected lower level of rate since there was no difference among sedentary workers (Table 3). The results of attitude and practice level on cholesterol management not having a significant difference between active and sedentary workers can be attributed to poor compliance with lifestyle changes despite the extensive literature and counseling available today to lower one's risk to hypercholesterolemia and CVDs. ${ }^{15}$ Based on the same study, several factors that can contribute to poor compliance with lifestyle changes may include reduced motivation, poor cognition, inaccurate health beliefs, and lack of clinical checkups.

Respondents who got an average score of $>50 \%$ from the measurement of knowledge were graded with a good score. The indicators for the income had respondents who got good score points wherein, those who earned the most (>P40,000) had the highest passing rate. The level of knowledge among the respondents varies from monetary earnings, with population from the highest earnings also had the highest level of knowledge towards cholesterol. ${ }^{16}$ This indicated that higher income results in more means of educating one's self about cholesterol management and its risk factors. Several sex differences were observed 
concerning knowledge assessment, wherein a majority of the total population reached the average target score, with the female having higher scores. FNRI revealed that most of the population who are at lower risk of $\mathrm{CV}$-related diseases in women. ${ }^{11}$ These results also revealed that the level of awareness towards cholesterol management is lower among males since they tend to engage in activities that are at high risk of developing CVDs. The level of knowledge, according to the education, showed association towards the average score points among the respondents. The results also implied that the civil status of an individual showed an association with knowledge. The respondents that got the highest scores from the variable of income indicated that the purchasing power of every individual is essential to access the resources in lacking, enough, or excessive amount. According to FNRI, a high prevalence of obesity among adults was found in the rich (37.0\%) and most abundant (43.7\%) group of population nationwide. ${ }^{11}$ The results also indicated that the level of attitude among the respondents varies from education and income. Similarly, the result for the practice assessment also indicated that the good points vary from education but not in income. Findings showed that college graduates tend to engage in risky practices such as smoking and drinking and are more likely to have unhealthy behaviors related to diet and exercise. Some factors to consider are their environment, social group, and the time they allot on their passions and careers, which are more likely to be on a higher scale compared to the other age groups. There was no reliable evidence about the lifestyle activities of adults according to the different age groups; however, overall assumptions from various studies stated that individuals who are more engaged in social activities in life have lower rates of all-cause mortality, CHDs, and CVDs. ${ }^{17}$

Studies about lipid and glucose had reported that age, education, and sex influence KAP on nutrition and quality of life. ${ }^{4,12,18}$ However, this study only showed sex and income to be significant. Outcomes may be attributed to certain limitations when the KAP study was carried out. The imbalance ratio of the subgroups may be considered. An unhealthy lifestyle is one of the modifiable risk factors that directly influence CVD development. ${ }^{19}$ Previous studies had shown a positive association of knowledge, attitude, and healthy living practices toward the risk factors of CVD morbidity and mortality. The effect of insufficient knowledge, attitudes, and practice towards the prevalence of the occurrence of CVD had been highlighted several times to various studies. ${ }^{20}$ One study about rural Bangladeshi adults had concluded that public health programs must be continuously updated and improved because it was vital to increase KAP on CV-related diseases and its implications. ${ }^{21}$ Based on the results of the study, $38.4 \%$ of the working adults from the total population exhibited physical inactivity during work. The majority of the respondents were observed to be engaging in an exercise routine.

\section{CONCLUSION}

The majority of the respondents had good knowledge, attitude, and practice scores. The highest rate was observed with the knowledge level of the population; however, lower ratios were observed for the right attitude and practices towards cholesterol management. In general, the factors of income and mobility had shown a significant effect on KAP scores. Overall, the majority of the population was observed to have a very low risk of hypercholesterolemia. Also, the overall KAP rate was found to be dependent only on the factors of sex and income. Despite the gaps in KAP measurement, respondents showed interest in cholesterol-lowering interventions. Further studies are therefore necessary to fill with a more concrete resolution.

\section{Recommendation}

The findings of the study have significant implications for further research, health policymakers, and national guidelines towards managing cholesterol levels as a risk factor of CV-related casualties. There is an assumption that improved knowledge will also improve one's attitude and excellent practice skills for a healthier lifestyle. Further research to examine the KAP for cholesterol management among adults who were previously or currently diagnosed with hypercholesterolemia should be done. The recommended study will give more information about the variations of their KAP levels in comparison to those undiagnosed adults. The need also for a more constructive set of questionnaires, focusing on more detailed answers to address the gaps between the measurements of KAP, should also be implemented. Lastly, equally strengthening public health promotion among the populations should also be done, since the growing burden of CVD risk factors among adults are observed regardless of the socioeconomic status.

\section{Strengths and limitations}

The study managed to accomplish a 100\% response rate despite having different location sites. The study sites also gave an opportunity to randomly select participants with varying ages and jobs to accurately determine the level of KAP towards cholesterol management in regards to the intensity of physical activity of an individual during work hours. This gave a more definite result to the findings for CVD risk reduction. It should be noted as well that the answers given by the respondents were all self-reported, and hence, the actual data to be reported might have been under or over-estimated since the respondents were all assumed as healthy in this setting. Another limitation of the study was that the questionnaires only covered limited scope regarding the previous and current life choices of an individual to measure the extent of keeping themselves healthy and free from developing $\mathrm{CV}$ and related diseases. 


\section{Statement of Authorship}

All authors contributed in the conceptualization of the research proposal, data collection and analysis. The lead author spearheaded the finalization of the research paper submitted.

\section{Author Disclosure}

All authors declared no conflicts of interest.

\section{Funding Source}

This study was funded by the Accelerated Science and Technology Human Resource Development ProgramNational Science Consortium (ASTHRDP-NSC) under the Department of Science and Technology (DOST).

\section{REFERENCES}

1. dela Sierra A, Pinto X, Guijarro C, Miranda JL, Callejo D, Cuervo $\mathrm{J}$, et al. Prevalence, treatment, and control of hypercholesterolemia in high cardiovascular risk patients: evidences from a systematic literature review in Spain. Adv Ther. 2015 Oct;32(10):944-61. doi: 10.1007/s12325-015-0252-y.

2. Lee YH, Lee SG, Lee MH, Kim JH, Lee BW, Kang ES, et al. Serum cholesterol concentration and prevalence, awareness, treatment and control of high low-density lipoprotein cholesterol in the Korea National Health and Nutrition Examination Surveys 20082010: beyond the tip of the iceberg. J Am Heart Assoc. 2014 Feb; 3(1):e000650. doi: 10.1161/JAHA.113.000650.

3. Catapano AL, Wiklund O, European Atherosclerosis Society. Think again about cholesterol survey. Atheroscler Suppl. 2015 Dec; 20:1-5. doi: 10.1016/S1567-5688(15)30011-8.

4. Pajak A, Szafraniec K, Polak M, Polakowska M, Kozela M, Piotrowski $\mathrm{W}$, et al. Changes in the prevalence, treatment, and control of hypercholesterolemia and other dyslipidemias over 10 years in Poland: the WOBASZ study. Pol Arch Med Wewn. 2016 Jul; 126(9):642-52. doi: 10.20452/pamw.3464.

5. PSA. Philippines Statistics Authority: Regional Quick Statistics 2018 [Internet]. 2018 [cited 2018 Feb]. Available from: https://www.psa. gov.ph/directory/civil-registration-department

6. Bennett JA, Stone KW, Nail LM, Scherer J. Definitions of sedentary in physical-activity-intervention trials: a summary of the literature. J Aging Phys Act. 2006 Oct;14(4):456-77. doi: 10.1123/japa.14.4.456.

7. De Smith MJ. Statistical Analysis Handbook: Comprehensive Handbook of Statistical Concepts, Techniques and Software Tools [Internet]. 2018 [cited $2018 \mathrm{Mar}$ ]. Available from: www.statsref.com

8. Haynes SN, Richard DCS, Kubany ES. Content validity in psychological assessment: a functional approach to concepts and methods. Psychol Assess. 1995 Sep; 7(3):238-47. doi: 10.1037/10403590.7.3.238
9. Larsson H, Tegern M, Monnier A, Skoglund J, Helander C, Persson $\mathrm{E}$, et al. Content validity index and intra- and inter-rater reliability of a new muscle strength/endurance test battery for Swedish soldiers. PLoS One. 2015 Jul; 10(7):e0132185. doi: 10.1371/journal. pone. 0132185 .

10. Taber KS. The use of Cronbach's alpha when developing and reporting research instruments in science education. Res Sci Educ. 2018; 48:1273-96. doi: 10.1007/s11165-016-9602-2.

11. 2015 Updating of the Nutritional Status of Filipino Children and other Population Groups [Internet]. 2018 [cited 2019 Feb]. Available from: https://www.fnri.dost.gov.ph/index.php/96-dissemination/1942015-updating-survey-result

12. Aminde LN, Takah N, Nagwasiri C, Noubiap JJ, Tindong M, Dzudie A, et al. Population awareness of cardiovascular disease and its risk factors in Buea, Cameroon. BMC Public Health. 2017 Jun;17(1):545. doi: 10.1186/s12889-017-4477-3.

13. Shiroma EJ, Lee IM. Physical activity and cardiovascular health: lessons learned from epidemiological studies across age, gender and race/ethnicity. Circulation. 2010 Aug; 122(7):743-52. doi: 10.1161/ CIRCULATIONAHA.109.914721.

14. Hari OS, Sonali G, Sumitra N. Awareness and trends of blood cholesterol and susceptibility to develop heart disease. Adv Genet Eng. 2015; 4:3. doi: 10.4172/2169-0111.1000138.

15. Mannu GS, Zaman MJS, Gupta A, Rehman HU, Myint PK. Evidence of lifestyle modification in the management of hypercholesterolemia. Curr Cardiol Rev. 2013 Feb; 9(1):2-14. doi: 10.2174/157340313805076313.

16. Frutuoso J, Bourbon M. The need to create awareness towards cholesterol. Atherosclerosis. 2016 Sep; 252:e1-e196. doi: 10.1016/j. atherosclerosis.2016.07.240

17. Kokubo Y. Prevention of hypertension and cardiovascular diseases: a comparison of lifestyle factors in Westerners and East Asians. Hypertension. 2014 Apr;63(4):655-60. doi: 10.1161/ HYPERTENSIONAHA.113.00543.

18. Mirmiran P, Mohammadi-Nasrabadi F, Omidvar N, HosseiniEsfahani F, Hamayeli-Mehrabani H, Mehrabi Y, et al. Nutritional knowledge, attitude and practice of Teheranian adults and their relation to serum lipids and lipoproteins: Teheran lipid and glucose study. Ann Nutr Metab. 2010;56(3):233-40. doi: 10.1159/000288313.

19. Cox JL, Vallis TM, Pfammatter A, Szpilfogel C, Carr B, O'Neill BJ. A novel approach to cardiovascular health by optimizing risk management (ANCHOR): behavioural modification in primary care effectively reduces global risk. Can J Cardiol. 2013 Nov; 29(11):1400-7. doi: 10.1016/j.cjca.2013.03.007.

20. Amarasekara P, de Silva A, Swarnamali H, Senarath U, Katulanda P. Knowledge, attitudes, and practices on lifestyle and cardiovascular risk factors among metabolic syndrome patients in an urban tertiary care institute in Sri Lanka. Asia Pac J Public Health. 2016 Jan;28 (1 Suppl):32S-40S. doi: 10.1177/1010539515612123.

21. Islam FM, Chakrabarti R, Dirani M, Islam MT, Ormsby G, Wahab $\mathrm{M}$, et al. Knowledge, attitudes and practice of diabetes in rural Bangladesh: the Bangladesh Population Based Diabetes and Eye Study (BPDES). PLoS One. 2014 Oct; 9(10):e110368. doi: 10.1371/ journal.pone.0110368. 